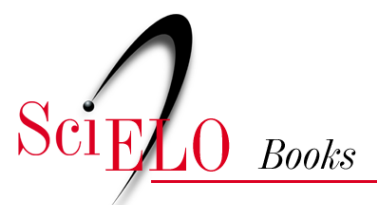

\title{
Uma História do Dr. Zigman Brener (abril de 1999)
}

\author{
Virgínia Schall
}

\section{SciELO Books / SciELO Livros / SciELO Libros}

SCHALL, V. Uma História do Dr. Zigman Brener (abril de 1999). In: Contos de Fatos: histórias de Manguinhos [online]. Rio de Janeiro: Editora FIOCRUZ, 2001, pp. 85-105. ISBN: 978-85-7541-6143. Available from: doi: $10.7476 / 9788575416143.0010$. Also available in ePUB from: http://books.scielo.org/id/hdq6f/epub/schall-9788575416143.epub.

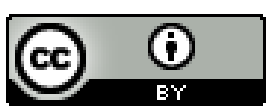

All the contents of this work, except where otherwise noted, is licensed under a Creative Commons Attribution $\underline{4.0 \text { International license. }}$

Todo o conteúdo deste trabalho, exceto quando houver ressalva, é publicado sob a licença Creative Commons Atribição 4.0. 


\title{
Uma História do \\ Dr. Zigman Brener \\ (abril de 1999)
}

\author{
Obomem tem sido chamado de microcosmo, \\ embora não tenhamospor ora nen humagrande \\ chave para destrancar aquelas câmaras secretas \\ onde as grandes leis de sua natureza são \\ reveladas; ainda estamos andando às tontas diante \\ daporta... Darrein, com sen estômago gritando \\ 'não', sua cabeça contrapondo 'sim', estara \\ silenciosamente virando a chare \\ Adrian Desmond \& James Moore
}

F $\mathrm{m}$ 1995, a Fiocruz sediou um evento em comemoração ao centenário da morte de Louis Pasteur, integrando-se às atividades programadas para celebrar o Ano Pasteur. O seminário, denominado Da Geração Espontânea à Evolução Molecular, foi organizado conjuntamente pela Fiocruz, Instituto Pasteur de Paris e Unesco como um dos eventos comemorativos planejados para os cinco continentes. Foram realizados seis simpósios internacionais, destinados a divulgar a importante obra do pesquisador, que revolucionou a medicina na segunda metade do século XIX e gerou contribuições valiosas para muitas outras áreas, tais como a agricultura, o meio ambiente e a indústria.

Na ocasião, o presidente da Fiocruz, Dr. Carlos Morel, solicitou ao Dr. Zigman Brener que apresentasse uma palestra durante o seminário. A platéia 
estaria repleta de pesquisadores de renome, dentre os quais alouns laureados com o Prêmio Nobel. Dr. Zigman é um respeitado parasitologista, com mais de duas centenas de trabalhos publicados, a maioria relacionada à doença de Chagas. Desafiado pela tarefa, o Dr. Zigman foi buscar fatos e dados da ciência que pudessem motivar os participantes para a sua apresentação.

Teria muito a falar do seu próprio trabalho, considerando-se a sua vasta produção científica ao longo de meio século de pesquisa. Sua contribuição ao conhecimento da esquistossomose e da doença de Chagas inclui a descrição de fenômenos importantes. Como exemplos: a verificação, em co-autoria com o Dr. Naftale Katz, da involução das formas graves de pacientes esquistossomóticos de áreas endêmicas tratados, que inspirou o trabalho inovador do Dr. Zilton Andrade sobre modulação do granuloma; a descoberta, em parceria com a Dra. Antoniana Kretlli, do anticorpo lítico, que permitiu aumentar a sensibilidade de diagnóstico de cura da doença de Chagas, e outros estudos sobre a evolução desta patologia e de seus aspectos imunológicos; e o teste, em colaboração com pesquisadores americanos, de cerca de seiscentas drogas para tratamento da doença de Chagas, o primeiro a evidenciar a eficácia de um dos dois únicos medicamentos hoje utilizados com sucesso - o Rochagan. Além disso, Dr. Zigman identificou outra substância bastante eficaz para o tratamento da doença, descrita em 1988 na tese de doutorado de sua orientanda, Leny de Sousa Filardi, e também em uma publicação na revista Transactions of the Rojal Society of Tropical MedicineandIHygiene (81: 755-759, 1987). Essa substância, denominada megazol, está sendo estudada em Farmanguinhos pelo Dr. Benjamim Gilbert e tem apresentado resultados promissores para o tratamento da doença de Chagas. Contudo, Dr. Zigman, em lugar de focalizar o próprio trabalho, decidiu abordar uma questão polêmica, ainda não bem resolvida, que tem sido motivo de discussões e diversas publicações, em torno da vida de um cientista fundamental para a biologia: Charles Darwin. E ele não só me contou essa história como me forneceu todo o material consultado para preparar sua conferência. Quando me vi diante de cerca de uma 
dezena de artigos publicados em revistas internacionais de excelente nível e um livro de 742 páginas, pensei que a tarefa não seria fácil. De fato, demandou tempo, mas assim que abrio livro e me debrucei sobre os artigos, mergulhei em um passeio fascinante pela vida do evolucionista, um verdadeiro mundo de revelações e o mais genuíno exemplo de abnegação e amor pela ciência, do compromisso incansável e quase obstinado com a busca de compreensão da nossa existência e origem.

\section{Polêmica Sobre a Saúde e a Morte de Charles Darwin}

Após as leituras, a vontade que dá é de contar resumidamente a vida de Darwin, de tocar nos pontos mais fenomenais de suas descobertas, mas essa tarefa já foi cumprida por historiadores diversos, e qualquer síntese correrásempre o risco de se tornar superficial e incompleta. Uma curiosidade incrivel é o seu extenso estudo das cracas, curioso animal marinho, que congrega várias espécies. Suas observações sistemáticas e meticulosas permitiram traçar uma linha evolutiva interessantíssima. Darwin conseguiu demonstrar a trajetória de especiação desse grupo, descrevendo as espécies mais primitivas, hermafroditas, seguidas de outras, heterossexuais rudimentares, em que se percebe a ocorrência evolutiva da diferenciação do macho - a qual, inicialmente, em algumas espécies, resume-se a um órgão sexual incrustado na fêmea -, passando por espécies em que o corpo vai se formando, até outras em que se observa um indivíduo macho, completo e separado da fêmea. Em nossa história humana recente, dominada pelo mundo masculino, a evidência da linha evolutiva das cracas suscita questões e gera conflitos; e se ainda hoje isso acontece, imagine-se seu impacto na época em que o cientista viveu.

O impacto de sua obra foi de tal ordem que a angústia vivida por Darwin, a manter em segredo por cerca de vinte anos a sua certeza - baseada em 
dados numerosos, obtidos e confirmados por meio de observações acuradas e sistemáticas - sobre o processo da evolução da vida só poderia resultar mesmo em tormenta, sobretudo numa época dominada pelo criacionismo. E é esse o Darwin que a nós apresentam os autores Adrian Desmond e James Moore no livro Darwin: a vida de um evolucionista atormentado (São Paulo: Geração Editorial, 1995). Em suas 742 páginas, os autores descrevem a vida e a obra de Darwin de modo extenso e detalhado, fruto de uma pesquisa de 12 anos na qual consultaram todas as fontes disponíveis, como num mergulho em tudo o que se guardou da sua vasta produção e de arquivos sobre sua vida, correspondências e repercussões de seu trabalho.

Mas antes de chegar aos fatos apresentados no livro, passemos ao foco desta história, a doença de Darwin, a qual tem motivado investigações e hipóteses e gerado diversas publicações. Um primeiro artigo sobre o tema, intitulado Charles Darwin and psicotherapy, foi publicado em 1943 pelo médico Douglas Hubble na revista The Lancet (30:129-133, jan.1943). A este artigo sucederam-se cerca de sete outros: em 1953, outro artigo do próprio Hubble; em 1959, um artigo de Saul Adler; em 1965, mais um, de autoria de A. W. Woodruff; em 1979, um de Rachel Lewinsohn, que cita também Kohn (1963) e Oliver et al. (1972); e em 1989, um de David Adler, que inclui algumas citações de capítulos de livros, como os de Keith (1955) e Pckering (1974), nos quais o assunto é comentado. Alguns dos autores, dentre eles Hubble e Woodruff, defendem a hipotése de ter sido a doença de Darwin uma psiconeurose; os demais tentam demonstrar que pode tratarse de uma doença tropical. Então, vejamos.

O artigo de Hubble de 1943 inicia-se por uma apresentação breve da biografia de Darwin, nascido em 1809 em Shrewsbury, Inglaterra, filho de um médico bem-sucedido e neto de Erasmus Darwin, renomado naturalista. O pai, depois de lutar com o filho, pouco afeito aos estudos e aficcionado dos esportes de campo, enviou Charles para estudar medicina em Edinburgh, Irlanda, onde havia uma das melhores escolas da Europa de então. Mas, Charles, após assistir a algumas cirurgias, decidiu que este não seria o seu 
caminho. O pai, percebendo desde cedo a predileção do filho por atividades de caça e coleta de animais, temia que ele se tornasse um "indolente esportista". Assim, enviou-o a Cambridge para fazer dele um clérigo. Entretanto, em Cambridge, Charles demonstrou mais interesse em colecionar besouros do que nos estudos e sermões. Naquele tempo, na Inglaterra, era comum os pastores religiosos assumirem reitorias rurais, associando a vida pastoral com os estudos naturalistas. Esta havia sido a escolha de seu primo, o pastor William Darwin Fox, também colecionador de besouros como ele, que Charles admirava e tomava como exemplo. Entretanto, em Cambridge, Darwin se tornou o aluno predileto do ministro religioso e professor de botânica e mineralogia, J. S. Henslow. Como renomado estudioso de geologia, Henslow foi convidado para viajar como naturalista a bordo do navio Beagle, mas, decidido a não se afastar da família e da universidade, indicou Darwin para tomar o seu lugar. Ainda que contra a vontade de seu pai, Darwin decidiu-se pela aventura com o capitão FitzRoy e em 1831 embarcou no navio Beagle como naturalista da expedição, a qual durou cinco anos.

Como Hubble relata, enquanto aguardava os preparativos do navio, nos meses de novembro e dezembro de 1831, Darwin registrou em trechos de seu diário uma primeira menção ao seu estado de saúde. Hubble cita a própria descrição feita por Darwin ao falar sobre o mal que sentia ao pensar em deixar toda a família e amigos por tão longo tempo. Queixa-se de sintomas como palpitação, dor no coração, tremor e náusea, convencido de que teria uma doença cardíaca. Mas decidiu não consultar nenhum médico, receoso de que o diagnóstico pudesse impedi-lo de viajar. Segundo Hubble, certamente tais sintomas não seriam correspondentes a uma doença cardíaca, dada a sua disposição física demonstrada durante a viagem no Beagle, nos cinco anos de pesado trabalho de coleta, em situações muitas vezes inóspitas e altitudes perigosas para um coração com problemas. Além disso, ele próprio associara os sintomas físicos às emoções despertadas pela separação da família.

Após a viagem no Beagle, Darwin trabalhou por dois anos em Londres, um período muito produtivo e em que ele próprio descreve mal-estares 
apenas ocasionais. Todavia, após o seu casamento, quando ainda residia em Londres, passou a se sentir mal com mais frequiência e a acreditar que pudesse ter uma doença crônica. Ele e sua esposa, pensando que o excesso de compromissos profissionais e o clima ruim de Londres poderiam estar associados aos seus problemas de saúde, decidiram viver no campo. Assim, compraram uma casa no condado de Down, onde viveram toda a sua vida, por cerca de quarenta anos. Hubble destaca o clima vitoriano da família, dos filhos numerosos, da afetividade entre Darwin e a esposa, da sua generosidade e da devoção da família a ele. A despeito da descrição dos seus repetidos momentos de mal-estar, sua família cresceu e seu trabalho científico prosseguiu com entusiasmo e intensa produtividade.

Hubble refere-se a uma biografia de Darwin, organizada por um de seus filhos, Francis, na qual ele descreve a rotina de trabalho do pai, suas refeições e seu descanso, intercalados com leituras científicas e literárias. Como conta, embora fosse sempre à mesma hora para a cama, Darwin não conseguia dormir: "Suas noites eram geralmente ruins, e ele freqüentemente mantinha-se acordado, sentindo desconforto na cama". Era como se, à noite, fosse perseguido pelos seus pensamentos, e ficasse exausto pelo trabalho incessante de sua mente, sempre ocupada por algum problema que o desafiara durante o dia e do qual ele não conseguia se desligar.

Segundo Hubble, após a referência aos problemas cardíacos no porto, em 1831, o mal-estar tornou-se quase diário a partir do seu casamento. Em uma carta ao colega J. D. Hooker em 1863, Darwin escreveu: "Tenho sentido uma contínua sensação de estômago cheio, leve dor e ligeiros espamos cardíacos. Mas como não apresento nenhum outro sintoma cardíaco, penso que meu coração não está afetado". Seu maior problema era de estômago, cujos sintomas Hubble associa a distúrbios emocionais, baseando-se em relatos do próprio Darwin: "Acredito não ter tido um único dia inteiro ou noite sem que meu estômago tenha apresentado sintomas nos últimos três anos... alguns amigos pensam que eu sou um hipocondríaco". 
Quando seu pai morreu, em 1848, ele se sentia tão mal, que não se viu em condições de viajar para ir ao enterro, chegando a se queixar de seu estado miserável, visto por Hubble como mais uma evidência de distúrbio emocional. É interessante notar sua percepção sobre o próprio mal-estar. Em seu diário, Darwin relata como gostava, durante a infância e juventude, de literatura (especialmente Shakespeare e o poeta Milton), arte e pintura e como, mais tarde, este seu prazer estético foi perdido, suplantado. Em suas palavras, "Minha mente parece ter se tornado uma espécie de máquina para estabelecer leis gerais a partir de uma vasta coleção de fatos, e isto parece ter causado a atrofia da parte do meu cérebro da qual a apreciação estética depende". Hubble comenta que talvez as preocupações psiconeuróticas tenham destruído a sua capacidade de apreciação estética.

Segundo Hubble, como naquela época não havia tratamentos para as psiconeuroses, Darwin procurou uma variedade de médicos para tratar seus sintomas físicos e só encontrou um certo alívio com a hidroterapia em balneários, chegando até a construir uma ducha no próprio quintal. Passou a tomar duchas diárias de água fria, alternadas com caminhadas em uma aléia lateral de sua casa. Relatou que essas medidas o deixavam exausto, fazendo-o ir para a cama às 8 horas, mais cedo do que usualmente, com melhor apetite e sem sintomas estomacais. Entretanto, tais efeitos foram temporários e o tormento e mal-estar retornaram. Depois de várias tentativas de diferentes tratamentos e médicos, Charles Darwin morreu de degeneração miocárdica em 19 de abril de 1882, com 74 anos.

Hubble afirma que os sintomas de Darwin podiam ser reconhecidos como neuróticos porque estavam associados com emoções negativas, como o excitamento provocado pelo desafio de não poder revelar a sua teoria em um ambiente não preparado para recebê-la. Hubble conclui também que a doença era usada por ele para evitar situações difíceis, já que nenhuma evidência física foi detectada e ele viveu até idade avançada. Apesar disso, Hubble conclui que a natureza, a origem e o desenvolvimento de sua dor emocional continuam obscuros. Ele, por vezes, acreditava ter uma fraqueza 
hereditária, que poderia inclusive transmitir aos filhos, e Hubble busca apresentar evidências de algum tipo de desordem nervosa em gerações anteriores de sua família. Para apoiar sua hipótese, Hubble refere-se também a aspectos do seu relacionamento com o pai, visto por Darwin como uma pessoa grandiosa em contraposição a ele. O próprio pai o considerava inapto, e assim o expressou certa vez: "Você não tem outro interesse senão por armas, cachorros e caçadas, e isto fará a sua desgraça e a de toda a sua família". Muitos anos mais tarde, Darwin escreveu que, em sua juventude, o pai fora injusto com ele.

Na visão de Hubble, os sintomas apresentados por Darwin - palpitação, tremor, náusea e vômito - eram expressões físicas de distúrbios psicológicos resultantes de intensa emoção. Hubble baseia-se num relato de Darwin, que, aos 15 anos, ao matar a sua primeira caça, descreveu o grau exagerado de excitação que experimentou, reforçando a hipótese de uma grande labilidade emocional, como se houvesse uma predisposição herdada para desenvolver uma psiconeurose. Hubble sugere ser este o caso de Darwin, associado ao valor adaptativo da patologia ao seu ambiente, pois ele era consciente de que a sua doença o protegia de gastar tempo com reuniões científicas e conversas sociais e de enfrentar publicamente as controvérsias despertadas pela publicação de $A$ Origem das Espécies.

Hubble encerra seu artigo apresentando algumas questões: como tratar Darwin em 1943? Seria fácil dizer ao autor de $A$ Origem das Espécies e de Expressão das Emoçõespelos Homense Animais que sua doença era um distúrbio autonômico característico de expressão emocional no homem, resultante de uma adaptação desfavorável ao ambiente? Mas a pergunta que se segue é: como saber se, uma vez restabelecida sua saúde, ele poderia ter levado a cabo a sua grandiosa obra? E apesar de toda a sua argumentação e tentativa de demonstração de fatos que poderiam comprovar a hipótese de uma psiconeurose, o próprio Hubble deixa dúvidas no ar.

Dez anos depois, em 1953, Douglas Hubble publica outro artigo na mesma The Lancet (26:1.351-1.354, 1953), intitulado The live of the shaw, 
no qual, para fortalecer o seu ponto de vista sobre uma provável psiconeurose, explora a melancolia e a hipocondria na família de Charles Darwin. Hubble apresenta um breve histórico sobre a evolução das concepções acerca de algumas doenças nervosas. Destaca que, de acordo com a mitologia do século XVI, a melancolia se expressa no fígado, no baço e na vesícula. A depressão era conhecida como hipocondria, e o fato de a melancolia se fazer acompanhar de sintomas físicos sustentava a sua hipótese. No século XIX, a hipocondria era considerada um estado semelhante ao que atualmente se define como ansiedade. Em 1796, Erasmus Darwin, avô de Charles, escrevia que "a doença hipocondríaca consiste em indigestão e conseqüente flatulência com ansiedade ou desejo de sensação de prazer". Sucessivas definições são citadas por Hubble, até chegar ao conceito expresso no dicionário de inglês de Oxford, que a designa como algo que o paciente imagina e acredita ter e que pensa ser grave. Assim, adotando tal definição e retomando algumas das evidências apontadas em seu artigo de 1943, Hubble destaca várias reminiscências da infância de Darwin que indicam ser a sua doença uma hipocondria. Associa então a doença ao ambiente e a uma certa imaturidade da personalidade de Darwin. Afirma que as duas horas de trabalho de observação e registro feitos pela manhã despertavam hipóteses que se mantinham em sua mente, provocando insônia, pois era à noite que o cientista sedimentava suas idéias. Traça a árvore genealógica de Darwin, demonstrando como ele, nascido em uma família de classe média alta, sem preocupações financeiras, dedicava-se ao interesse científico, destacando a sua genialidade associada à hipocondria, esta última observada em vários dos seus filhos.

Hubble retoma a cronologia dos fatos sobre a hipocondria de Darwin desde os primeiros sintomas descritos pela primeira vez no porto de Plymouth, em 1831. Gozando de boa saúde desde então até 1839, Darwin adoece após seu casamento, durante a gravidez de sua esposa, e permanece incapaz de trabalhar por dois anos. Assim, segundo Hubble, seus papéis de marido e mulher se definem como o de marido inválido e o de esposa enfer- 
meira dedicada. "A enfermeira perfeita casou-se com o paciente perfeito", de acordo com Mrs. Raverat, neta de Darwin, em seu livro sobre a família (London: Period Piece, 1952). Muitos amigos, observando a aparência robusta de Darwin associada às suas descrições de noites de insônia e distúrbios, não tinham dúvida de que se tratava de hipocondria. Como interpreta Hubble, Charles bem cedo aprendeu, em seu contato com um pai autoritário e tirânico, a descar regar a agressão por meio de seu sistema autonômico, expressa, em seu próprio corpo, com distúrbios gastrointestinais.

Descrevendo o ambiente familiar de Darwin em Down como idílico e pleno de afetividade, Hubble argumenta que a afetividade em excesso provoca ansiedade e a segurança oferece por si só um medo da insegurança, justificando a tendência hipocondríaca de vários de seus filhos. Assim, afirma que dos sete filhos de Darwin que chegaram à idade adulta (nasceram dez), apenas dois escaparam à hipocondria. Hubble descreve as peculiaridades da hiponcondria dos cinco filhos, utilizando como fonte o livro de Mrs. Raverat. Hipocondria requer, para sua patogenia, não apenas uma personalidade imatura mas um ambiente de excesso de cuidado, o que havia de sobra em Down House. Mas, a conclusão de Hubble, após analisar a família de Darwin - pais, irmãos e filhos - é que a evidência de uma baixa vitalidade e depressão orgânica familiar não é forte, o que o leva a destacar a importância do ambiente no desenvolvimento de suas personalidades. Dessa forma, mais uma vez, o próprio autor não consegue fortalecer a hipótese de psiconeurose, a qual permanece como uma mera sugestão.

Um terceiro artigo, intitulado Darwin's illness, de Saul Adler, publicado em 1959 no Nature (184:1.102-1.103, 1959), introduz uma nova perspectiva sobre a doença de Darwin, sugerindo tratar-se da doença de Chagas, contraída durante a sua viagem no Beagle, quando este passou pela América do Sul. Assim, o enfoque de Hubble é transposto da esfera da psiquiatria para o da medicina tropical. O episódio sobre o possível contágio advém da descrição feita pelo próprio Darwin em seu diário de bordo quando de sua passagem pela província de Mendoza, ao pé dos Andes, na Argentina, 
em 1835. Ele descreve os ataques de barbeiros (benchuca) gigantes e como era "hornivelmente repugnante acordar à noite e senti-los, com uma polegada de comprimento (...) negros e macios, rastejando sobre o seu corpo refartos com seu sangue". Essa descrição também está presente em um artigo do pesquisador de Manguinhos, Dr. Herman Lent, ${ }^{26}$ no qual ele relata a passagem do livro de Darwin citada por Adler e vai além. No trecho traduzido por Lent, Darwin diz que "se lhe fosse apresentado um dedo, 0 ousado inseto imediatamente projetava o sugador, investia e, se tho permitissem, retirava sangue. A mordida não lhe causava nenhuma dor. Era curioso observar-lhe, enquanto sugava, a transformação que sofria o corpo, passando, em menos de dez minutos, de um pequeno folhado a um globo intumescido. Esse banquete único a benchuca deveu-o a um dos oficiais e valeu-lhe quatro meses inteiros; mas, passadas duas semanas, estava novamente pronta para nova festança". Como afirma Adler, tais barbeiros eram certamente da espécie Triatoma infestans, o principal vetor da doença de Chagas ou tripanosomíase americana. Adler descreve as características da doença de Chagas, enfatizando o comprometimento do miocárdio, os distúrbios cardíacos e os danos para o esôfago e cólon (a doença causa dilatação desses órgãos) associados a sintomas como disfagia, regurgitação de alimentos, vômitos ou constipação. Cita também diversos estudos que demonstraram um grande número de pacientes que não manifestam sintomas físicos, apesar de apresentarem reações positivas nos testes de diagnóstico da doença.

Esta hipótese de Adler foi seriamente contestada por A. W. Woodruff, que publicou em $1965 \mathrm{o}$ artigo Health in relation to his voyage to South America, no BritshMedical Journal (1:745-750, 1965). Refutando Adler ponto por ponto e retomando o ponto de vista de Hubble, Woodruff reafirmou

\footnotetext{
${ }^{26}$ LENT, H. Estado atual dos estudos sobre os transmissores da doença de Chagas, Anais do Congresso Internacional da Doença de Chagas, 1959:739-760.
} 
a defesa do diagnóstico de psiconeurose. Menciona o mal-estar relatado por Darwin no porto, com sintomas iguais aos que veio a manifestar mais tarde pelo resto da vida, como uma prova de que estes eram causados por distúrbio nervoso e antecediam à postulada infecção pelo Trypanosomacruzi. Reforça a sua tese com a descrição detalhada de outros sintomas apresentados na ocasião em que aguardava a saída do Beagle, como um tremor nos dedos e dermatite, relatados em uma carta de Darwin para a sua irmã, na qual ele the pede que consulte o pai sobre a conveninência de tomar uma dose de arsênico por um curto período. Na carta, Darwin sugere que seu mal-estar se devia à mudança na sua maneira de viver e que tudo voltaria a estar bem quando voltasse ao estilo de vida anterior.

Woodruff segue questionando Adler - apoiando-se em evidências da vida de Darwin que descartam qualquer sinal de anormalidade física, em sua disposição para caminhadas e cavalgadas diárias e na exacerbação dos sintomas nas ocasiões em que ele se via sob estresse emocional - e exclui a possibilidade de haver qualquer base orgânica para sua doença. Em um tópico dedicado à análise epidemiológica, admite que $70 \%$ dos barbeiros de Mendoza encontravam-se positivos para o Trypanosoma cruzi, mas na população humana o índice de infecção era bem menor e em idades que sugeriam um contato mais prolongado com o inseto vetor. Assim, sugere que para contrair a doença seria preciso estar em contato com o barbeiro por mais do que uma única exposição, o que não acontecera com Darwin. Além disso, Woodruff apresenta uma tabela correspondente a um inventário histórico das doenças que acometeram a tripulação do Beagle de 1932 a 1936, demonstrando que ninguém mais apresentou sinais semelhantes aos da doença de Chagas, a despeito de vários terem sido atacados pelos barbeiros. Como Hubble, Woodruff focaliza a natureza da doença com base em uma análise da família de Darwin, concluindo que os sintomas apresentados por Darwin foram também observados em vários de seus filhos, sem que nenhum deles tivesse estado em Mendoza, e sugerindo que haveria uma tendência familiar e um ambiente favorável à psiconeurose, 
em contraposição à tese da tripanossomíase. Deșcreve o curso de evolução da doença de Darwin, demonstrando a atenuação dos sintomas nos últimos dez anos de sua vida como resultado de uma certa paz alcançada na idade mais avançada, compatível com um diagnóstico de psiconeurose, muito mais do que com o da doença de Chagas. Embora argumente com mais vigor e firmeza do que Hubble, algumas de suas afirmações podem ser contestadas, e de fato o são, em publicações subseqüentes.

Cerca de 14 anos após a publicação de Woodruff, mais um artigo retoma a hipótese da doença de Chagas. Trata-se do trabalho de Rachel Lewinsohn The discovery of Trypanosoma cruzi and of American Trypanosomiasis: foot-notes to the history of Chagas's disease, publicado no Transactions of the Royal Society of Tropical Medicine and Hygiene $(73: 513-523,1979)$. A pesquisadora apresenta um extenso artigo histórico sobre a descoberta da doença de Chagas, baseado nas descrições de Carlos Chagas Filho, com reproduções de fotomicrografias de trabalhos originais de Carlos Chagas publicados nas Memórias do Instituto Oswaldo Cruz (1:159-218, 1909 e 3:219$275,1911)$. Relata detalhadamente a história da menina Berenice, primeiro caso humano diagnosticado por Chagas em Lassance, Minas Gerais, cidade onde a endemia foi descoberta pelo pesquisador. Lewinsohn inclui dados de pesquisadores brasileiros que acompanharam Berenice até uma idade avançada e afirma que, relendo os artigos sobre a doença de Darwin após conhecer os dados do caso Berenice, experimentou um curioso sentimento de déja ru. Assim, a pesquisadora argumenta que os sintomas de Darwin, mesmo que aparentemente relacionados a distúrbios mais emocionais do que físicos, apresentam um estreito paralelo com o caso de Berenice, cujas queixas de palpitações e dores precordiais também eram exarcebadas por emoções. Vivendo em áreas rurais no Brasil, Berenice não tinha como evitar tarefas que demandavam severo esforço físico, o que não provocava sintomas cardíacos, outro paralelo com o caso de Darwin. Berenice viveu até idade avançada, com sistema cardiovascular intacto. Lewinsohn cita ainda os trabalhos de Koeberle publicados entre 1957 e 1974, como uma nova luz 
na compreensão da evolução da doença de Chagas. Esse autor demonstrou um efeito significativo dos distúrbios neurovegetativos da fase aguda da doença de Chagas associados a sintomas psíquicos tardios nos pacientes, 0 que foi observado no caso de Berenice, sendo possível afirmar que lesões do seu sistema neurovegetativo na fase aguda poderiam ter deixado seqüelas em sua psique. Segundo Koeberle, o paciente com doença de Chagas crônica é um neurótico vegetativo, e a doença, uma distonia vegetativa predominantemente simpatotônica. A vitima está sempre cansada, irritada, agitada, reclama de insônia e apresenta incontáveis sintomas do vago. Tais sintomas podem ter levado os autores anteriores a diagnosticar a doença de Darwin como psíquica, sobretudo pelos sintomas semelhantes por ele descritos antes do embarque no Beagle. Os argumentos e novas evidências sobre a evolução e características de pacientes chagásicos crônicos incluem assim um novo ingrediente na polêmica sobre a natureza da doença de Darwin, reforçando as suspeitas quanto à doença de Chagas.

Dez anos após a publicação de Lewinsohn, o artigo de David Adler Darwin's illness - publicado no Israel Journal of Medicine Science (25:218-221, 1989) renova a defesa da tese da doença de Chagas. $D$. Adler inicia o artigo descrevendo as características da doença de Chagas e associando-as aos sintomas apresentados por Darwin ao longo da vida, num paralelo entre o seu caso e centenas de casos similares estudados no Brasil. Inclui um trecho de uma carta enviada a Hooker, no qual Darwin afirma que acredita não ter uma única noite ou dia sem desordens estomacais, supondo uma piora à noite que indica uma provável lesão no trato digestivo, provocando regurgitação. Essa exacerbação noturna poderia estar relacionada à sua insônia. Adler questiona o argumento de Woodruf, que, referindo-se a um curto período de queixas no porto de Plymonth, sustentava serem os sintomas de Darwin anteriores à viagem no Beagle. Como indica Adler, há, em contraponto a tal referência, incontáveis evidências da boa saúde de Darwin em Cambridge, onde fazia caminhadas e escaladas, participava de clubes de gourmets, inclusive um de comidas exóticas, assim como seu vigor 
e seu gosto pela culinária do Beagle e dos países visitados, sem qualquer referência a mal-estar estomacal durante esses anos. Considerando os anos de latência da doença de Chagas até a manifestação dos primeiros sintomas, verifica-se coincidência com o período no qual ele começa a apresentar sintomas contínuos de mal-estar, precisamente cerca de três anos após o retorno da viagem. Em um questionário respondido por Darwin aplicado por Galton em 1873, Darwin afirma sobre a sua saúde: "Boa quando jovem, ruim a partir dos 33 anos”. Adler afirma que é difícil entender a omissão de Woodruff sobre a boa saúde de Darwin durante a viagem no Beagle, questionando a seleção tendenciosa das evidências citadas.

Embora sem certezas conclusivas, as últimas publicações apresentam argumentos que favorecem o diagnóstico da doença de Chagas, polêmica que ainda pode ser retomada, tendo em vista o caráter mais especulativo dos artigos.

Movida pela curiosidade despertada pelos artigos sobre a saúde de Darwin, encontrei alguns aspectos adicionais descritos no livro Darrein: a vidadeumerolucionistaatormentado, de Adrian Desmond e James Moore (São Paulo: Geração Editorial, 1995) que podem gerar mais especulações. Apresento-os a seguir.

Embora todos os autores dos artigos supracitados só relatem evidências de problemas de saúde quando Darwin se achava no porto, à espera de partir no Beagle, o livro de Desmond \& Moore descreve problemas inflamatórios e estomacais bem anteriores. Em 1827, Charles, que contava então com 18 anos, fez sua primeira viagem a Paris com um tio e, segundo contam os autores, "Ele mal sobreviveu à chuvosa travessia. Ainda que 'não estivesse muito bem', conseguiu engolir um jantar substancial de rosbife a bordo" (p. 64).

Outro fato instigante refere-se a um incidente na caça de besouros, uma mania que, segundo Desmond \& Moore, varria a Inglaterra de então e se espalhara também por Cambridge, onde Charles fora estudar, após deixar a medicina em Edimburgo. Muitos moradores enchiam estojos desses 
animais e a bíblia de Charles na época era um manual de quatro volumes, AnIntroductionto Entomology. Como descrevem os autores, "Um dia, ao tirar a casca de uma árvore morta, ele capturou dois tipos raros, um em cada mão. De repente avistou uma terceira nova espécie, boa demais para ser perdida. (...) Escondeu o besouro da mão direita na boca. Infelizmente tratava-se de um besouro-bombardero, o qual prontamente fez jus ao nome, esguichando um nocivo fluido fervente na garganta de Charles, apalermando-o momentaneamente" (p. 77-78).

Poderia esse fluido ter algo a ver com episódios posteriores de inflamação na boca e com sua doença estomacal, ou o seu mal estaria relacionado a estresse emocional? Ou o que era devido a estresse se agravou devido à doença de Chagas, possivelmente contraída na América do Sul? O certo é que, sem que se saiba por quê, quando Charles era ainda jovem surgiram episódios repetidos de inflamação na boca que chegavam a deixá-lo acamado. Uma primeira referência ocorre em suas férias de verão na casa do tio, em Shrewsbury, pouco antes dos seus vinte anos. Durante a sua diversão predileta, as caçadas, um dos companheiros foi ferido no olho por uma cápsula de percussão. Como relatam Desmond \& 2 Moore, "Charles nunca ficara 'metade tão aterrorizado' à visão de sangue" (p. 83). De volta à casa, apresentou uma lesão em si mesmo, lábios inflamados, tão doloridos, que Charles passou a tomar " 'pequenas doses' de arsênico para alívio" (p. 83). Ficou de cama semanas, perdeu a viagem que faria e só depois do vigésimo aniversário a boca sarou e ele foi para Londres, a caminho de Cambridge.

Novas referências sobre essa inflamação nos lábios, que se repete algumas vezes, são feitas pelos autores. Novamente em Cambridge, Darwin sentia-se só e entediado e, como relatam os autores, "seus lábios o estavam fazendo sofrer" (p. 86). A associação com estresse é plausível, já que era uma época de grande ansiedade devida à proximidade do exame Little Go, definitivo para a sua formação.

Desmond e Morris encontram em seu diário o registro de que seus lábios voltaram a inflamar: "Ele estava acamado. Estivera entomologizando 
com o reverendo Hope no norte de Gales em meados de junho, quando seus lábios inflamaram; dirigiu-se, então, para casa novamente, 'com lamento e pesar', para ser velado pelo doutor e suas irmãs. Hope enviou alguns espantosos besouros saltadores, elatérides, para animá-lo - insetos 'vermelho-brilhantes'-, mas com sua própria boca vermelha, aquilo parecia piada de mau gosto" (p. 93-94).

Era época de férias de verão em Shrewsbury, mas ele estava preocupado com o exame preliminar para a sua formação, e sua recuperação durou duas semanas.

Na página 101, os autores sugerem que naquele verão seus lábios colaboraram. Desmond \& Moore relatam que, muitos anos mais tarde, quando a doença estomacal de Darwin se tornara crônica, seu médico londrino, Dr. Holland, chega a diagnosticar a doença de Charles como 'gota reprimida', como se, de modo similar à gota do pai, a dele agisse internamente, no estômago: "Holland atribuía a causa a venenos no sangue que ativavam uma predisposição hereditária” (p. 383).

Depois dos episódios da inflamação na boca, outras questões de saúde aparecem na época da partida no Beagle, a qual foi adiada várias vezes por problemas operacionais ou climáticos. Darwin, deprimido com tantos atrasos, preocupava-se com o enjôo e era torturado por pensamentos de morte. Ao saber que um marinheiro havia escorregado no navio e se afogara, "percebeu seu coração palpitando e desenvolveu dores no peito. Aquilo era doença cardíaca? Ele ocultou seus medos... se seu pai descobrisse, ele o impediria de ir" (p. 129). Esse relato foi apontado pelos autores dos artigos acima citados como a primeira evidência de problemas de saúde antes da viagem.

Retomando o livro: Desmond \& Moore contam que finalmente o navio partiu, no dia 5 de dezembro, e, então, "a miséria de Charles começou imediatamente" (p. 131). A náusea arrastou-o até a amurada e ele despejou seu café da manhã sobre as ondas. Nada ficou no estômago pelo dia todo. Depois de uma parada para o Natal, o Beagle partiu de novo, e Charles 
relata em seu diário que nada ficou no seu estômago por dez dias, exceto "biscoitos secos e uvas passas" (p. 133).

Muitas passagens do livro foram marcadas pelo Dr. Zigman, várias delas sugerindo sintomas da doença de Chagas, como o relato de que Darwin, após o retorno da viagem no Beagle, já morando em Londres e reconhecido por seu trabalho, recusou o cargo de secretário na Sociedade Geológica, em 1837 (estava com 28 anos). Entre as desculpas para sua recusa, diz que "qualquer coisa que me deixe nervoso me extenua completamente em seguida e me traz uma feia palpitação no coração" (p. 253).

Charles pensava no seu casamento e no seu futuro: "Tinha vinte e nove anos de idade, seu coração estava com problemas e defrontava a vida solitário" (p. 262). Também na passagem em que escrevia sobre a teoria da transmutação das espécies, a saúde o incomodava: "A transmutação ainda afetava a boca de seu estômago, mas ele aprendera a dar longas caminhadas para se revigorar" (p. 266). As caminhadas eram recomendação do pai, que "falava em "ser cauteloso e empreender caminhadas, como um bom rapaz". "Eu abomino o fato de seu colapso [lhe diria o pai]" (p. 346).

Desmond \& Moore relatam que, em junho de 1938, aos 29 anos, ele estava atolado de trabalho e "sua doença intensificou-se (...) o estômago ruim e as dores de cabeça acompanharam um coração irrequieto": Diante da labuta que o aguardava para descrever o material recolhido durante a viagem no Beagle, escreveu: "Espero poder ser capaz de trabalhar bem duro durante os próximos três anos... mas descubro que a cachola e o estômago são poderes antagônicos, e que é muitíssimo mais fácil pensar demais em um dia do que pensar muito pouco - o que o pensamento tem a ver com digerir rosbife, eu não sei dizer" (p. 270).

Segundo os autores dos artigos referidos, a doença crônica de Darwin surgira depois de seu casamento. Um dos autores chega até a precisar a época: a ocasião em que sua mulher fica grávida do primeiro filho. Mas, como se lê nos relatos de Desmond \& Moore, quando se achava em Londres, ainda solteiro, Darwin registrou em seu diário vários episódios de mal 
estomacal e cardíaco. Desde então a doença foi se agravando, e os autores relatam que, em 1845, "Ele estava vomitando novamente; o velho malestar estava pior do que nunca. Seu estômago não estivera bem por uma noite sequer desde que se mudara para Down e isto fazia com que se dedicasse ao trabalho nas poucas horas diárias em que se sentia melhor. Amigos pensavam que ele era um hipocondríaco, porque sempre tomava a doença como uma desculpa... Mas ele não era um falso doente. A doença era verdadeira e arrebatadora, embora ninguém soubesse o que a causava. Ele tentava todos os tipos de remédios" (p. 355).

Em 1847, os problemas o afligem novamente: "O problema é que continuava com espasmos ininterruptos. Durante semanas, ao longo de março e abril, esteve quase sempre doente, atormentado por 'queimações e engasgos" " (p.365). Isso continua: ficava "deitado no sofá, com queimações 'furiosamente reinflamadas' e um mal-estar debilitante" (p. 370). Foi visitar o pai doente em Shrewsbury, mas permaneceu deitado durante dias, "resmungando e gemendo, tomado pela praga da queimação". E o diário revela que, em 1848, visitando novamente o pai, que estava muito mal, "o meu confuso estômago (...) tem estado cada vez pior” (p. 377). Sua doença se agravara alarmantemente: enquanto via o seu próprio pai definhando, "não podia esquecer do seu estômago nem por cinco minutos" (p. 378).

O livro que escrevia tornava-se demasiado grande e a enorme tarefa o fazia afirmar que "o trabalho me testa o tempo todo e faz meu coração palpitar" (p. 466). Desmond e Moore afir mam que sua mulher, Emma, "já notara havia muito tempo que a saúde de Charles era afetada por sua mente e sua cabeça estava perturbada". Realmente, o livro crescia em proporções exageradas, e "seus nervos estavam à flor da pele, seu coração continuava palpitante" (p. 468). Nem a hidroterapia o atraía mais. "Tentou medicina alternativa, tomando alguns preparados à base de ácido no caso de seus sucos gástricos estarem precisando de reforço." Os autores revelam que a hidroterapia o distrai de pensar nas espécies e, como ele mesmo explicou a Hooker, lhe proporciona alívio: "Isto é bastante inexplicável - posso 
caminhar e comer como um cristão robusto; e mesmo minhas noites são boas. Não consigo nem de longe entender como a hidroterapia pode agir, como certamente age em mim. Ela amortece esplendidamente o cérebro de uma pessoa, não penso em uma única espécie de qualquer tipo desde que deixei minha cas." (p. 475).

Mas, em 1859, Darwin faz cinquienta anos e a saúde volta a piorar. Trabalhava ansioso por terminaro livro: "Quinze desagradáveis meses foram completados em $1^{\circ}$ de outubro, quando Charles terminou as provas no meio de ataques de vômitos. Durante todo esse tempo ele raramente foi capaz de escrever sem sentir dores estomacais por mais de vinte minutos no máximo" (p. 497).

Sob pressão das provas do livro, ainda escreve: "Tenho estado muito mal ultimamente... uma perna inchou como se fosse elefantíase, os olhos quase se fecharam, cobertos com horríveis e dolorosas bolhas... - era como estar vivendo no inferno" (p. 497).

Em 1861, no inverno, os amigos o encontram visivelmente envelhecido e com uma inflamação na pele que o deixava descamando como réptil. Desmond \& Moore relatam que "de maneira horripilante (...) o eczema havia tirado completamente sua epiderme uma dúzia de vezes" (p. 534). Mais adiante, o registro de que Charles vomitava tanto que Emma diria: "Isso corta o meu coração" (p. 536). Também sentia "uma dor de cabeça infernal" e ânsias de vômito, tendo inclusive enviado amostras de seu conteúdo para análise, mas sem resultado. Assim, a saúde de Darwin ia de mal a pior, tanto que o título do capítulo 35 do livro de Desmond \& Moore, no qual o mostram "definhando lentamente", chegando a desejar morrer a qualquer momento, é 'Vivendo num túmulo' (p. 539). Por 27 dias seguidos vomitou após cada refeição e várias vezes durante a noite. A doença durou até a primavera de 1864, quando teve uma pequena melhora até estar horrivelmente mal, tanto que acreditava jamais terminar o livro sobre domesticação de animais que estava escrevendo. Convidou um especialista em dispepsia e medicina psicológica para examiná-lo e descreveu assim os 
próprios sintomas: "Durante 25 anos convulsões extremas diariamente e flatulência noturna: vômitos ocasionais, em duas ocasiões prolongado durante meses. Vômitos precedidos por calafrios, choro histérico (,) sensação de desfalecimento ou meio-desmaio. E urina copiosa muito pálida. Vomitando agora e toda passagem de flatulência precedida por badaladas nos ouvidos, passos no ar e visões. Foco e pontos pretos (,) fadiga, especialmente perigosa, leva aos sintomas na cabeça (,) nervosismo quando Emma me deixa" (p. 550).

O mal era tamanho, que seu amigo Hooker compara o Darwin do ano anterior, robusto e com um porte parecido ao de Moisés do afresco da Casa dos Lordes, com o atual, desfigurado, de olhos embaçados e rosto encovado. E assim continuou, alternando períodos péssimos com alguns toleráveis até viver episódios de sofrimento grave em 1881 e falecer em 1882. Na página 62, Dr. Zigman assinalou um trecho que parece indicar sintomas de angina. Numa tentativa de subir uma montanha, ele desmaiou e o médico considerou as suas condições cardíacas precárias, prescrevendo descanso sem mais escaladas. Teve ataques e já tomava morfina para a dor. Até o fim escrevia em seu diário enunca perdeu o entusiasmo pelas espécies, sempre atento e observador. Em uma quarta-feira, 19 de abril de 1882, sua vida cessou, não antes de dizer aos filhos "para se lembrarem do quanto foram bons para mim". 


\section{Zigman Brener ${ }^{27}$}

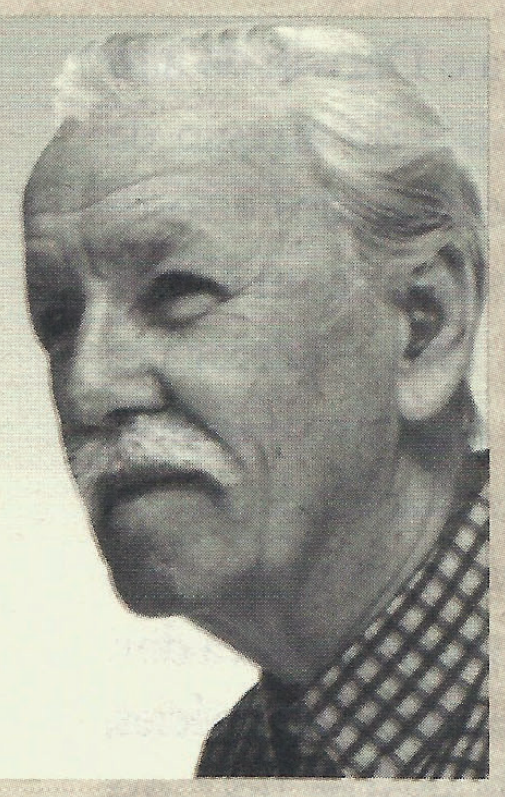

Dr. Zigman Brener nasceu em são Paulo no dia 07 de setembro de 1928. Formou-se médico pela Faculdade de Medicina da UFMG em 1953. Tornou-se doutor em medicina em 1957, também pela UFMG, ao defender a tese intitulada Calazar Canino em Minas Gerais. Pouco depois, em 1961, tornou-se livredocente da cadeira de zoologia e parasitologia da Faculdade de Farmácia e Bioquímica da UFMG e logo a seguir, em 1962, professor catedrático de zoologia e parasitologia da mesma faculdade. Em 1968, passou a professor titular do Departamento de Parasitologia do Instituto de Ciências Biológicas da UFMG, tornando-se, no ano seguinte, 1969, coordenador do curso de pós-graduação em parasitologia em nível de mestrado do Departamento de Parasitologia do Instituto de Ciências Biológicas, também da UFMG. Há muitos anos é professor e orientador no curso de pós-graduação em biologia celular e molecular do IOC/Fiocruz. É também professor emérito do Departamento de Parasitologia, Instituto de Ciências Biológicas, UFMG, condecorado em 1994 e chefe do Laboratório de Doença de Chagas do CPqRR/Fiocruz. Foi diretor científico do CPqRR de 1978 a 1984. É bolsista do Conselho Nacional de Desenvolvimento Científico e Tecnológico (CNPq), na categoria de Pesquisador IA. É membro fundador da sociedade

\footnotetext{
${ }^{27}$ Texto extraído de seu curriculum vitae.
} 
Brasileira de Medicina Tropical; é membro da Sociedade Brasileira de Protozoologia e da Federação Latino-Americana de Parasitologia; membro titular da Academia Brasileira de Ciências, Seção de Ciências Biológicas, eleito em 1980, e membro honorário da Sociedade Internacional de Protozoologia, eleito em 1984. Foi admitido na ordem Nacional do Mérito Científico, na classe Grã-Cruz da ordem, pelo Decreto de 6 de setembro de 1994. Destaca-se a sua permanente colaboração como consultor de vários comitês científicos, seja como presidente ou participante, incluindo vários steering committee do Tropical Diseases Research da OMS, de 1977 a 1993; de diversos comitês assessores do CNPq e da Financiadora de Estudos e Projetos (Finep), em 1984 e em 1992-1993; da Fundação de Amparo à Pesquisa de Minas Gerais (Fapemig), de 1985 a 1997; da Fundação Ezequiel Dias (Funed); e da Secretaria de Saúde do Estado de Minas Gerais (1992-1998). Integra, desde 1993, o Conselho Editorial da Editora Fiocruz. orientou cerca de trinta alunos de mestrado e doutorado, muitos dos quais são hoje destacados pesquisadores. Publicou mais de duzentos trabalhos científicos em revistas nacionais e internacionais. contribuiu significativamente para o conhecimento da doença de chagas, incluindo melhoria dos métodos de diagnóstico e avaliação das drogas hoje utilizadas em seu tratamento. 